\title{
Miranda
}

Revue pluridisciplinaire du monde anglophone /

Multidisciplinary peer-reviewed journal on the English-

speaking world

$10 \mid 2014$

Images on the Move: Circulations and Transfers in film

\section{The paradoxes of cinematic movement: is the road movie a static genre?}

Anne Hurault-Paupe

OpenEdition

Journals

Electronic version

URL: http://journals.openedition.org/miranda/6257

DOI: $10.4000 /$ miranda.6257

ISSN: 2108-6559

Publisher

Université Toulouse - Jean Jaurès

Electronic reference

Anne Hurault-Paupe, "The paradoxes of cinematic movement: is the road movie a static genre?",

Miranda [Online], 10 | 2014, Online since 23 February 2015, connection on 16 February 2021. URL:

http://journals.openedition.org/miranda/6257 ; DOl: https://doi.org/10.4000/miranda.6257

This text was automatically generated on 16 February 2021.

\section{(c) (1) $(9)$}

Miranda is licensed under a Creative Commons Attribution-NonCommercial-NoDerivatives 4.0 International License. 


\title{
The paradoxes of cinematic movement: is the road movie a static genre?
}

\author{
Anne Hurault-Paupe
}

1 Filmic movement is such a complex notion that it only recently emerged as a field of study, from Gilles Deleuze's Cinema 1: The Movement Image, to consideration of motion and stillness in video and digital images (Rossaak 15-16; Chik 139-150). The road movie is an ideal genre with which to question theories of movement, as its very name anchors it in (primarily automotive) travelling. The purpose of this article will be to question the very notions of stasis and movement in the road movie: what is it that moves in this genre? I will use as a starting point previous work which concluded that the road movie presents a contemplative, almost static vision of reality (Hurault-Paupe 2006). How can a genre that seems to be dedicated to showing movement give a static impression? Is this due to the slowness of the camera moves in this genre, or to the camera's lack of movement? Or is it caused by the quality of the movement, to its rhythm, fluidity, or orientation; is it created by editing? In other words, is movement in a specific genre something which should be evaluated at the level of the segment, or at the level of the film as a whole?

\section{Genre analysis methodology}

2 Studying road movies, like any other genre analysis, implies defining a specific corpus of films which can be considered as road movies. However, this pivotal first step is in itself arduous: if a thematic definition of the genre is used to circumscribe the corpus, the resulting analysis is likely to lead to tautological conclusions. For instance, if one assumes that "road movies are films in which traveling is a central element," one will probably find that the films in the corpus did indeed focus on characters who travel, and hence, that movement is a central element in those films. In a study of the Western film, Andrew Tudor faced a similar hurdle, which he described as a "vicious circle:" 
[A]lmost all writers using the term genre [...] are caught in a dilemma. They are defining a "Western" on the basis of analyzing a body of films which cannot possibly be said to be "Westerns" until after the analysis. [...] To take a genre such as the "Western," analyze it, and list its principal characteristics, is to beg the question that we must first isolate the body of films which are "Westerns." But they can only be isolated on the basis of the "principal characteristics," which can only be discovered from the films themselves after they have been isolated. That is, we are caught in a circle which first requires that the films are isolated, for which purposes a criterion is necessary, but the criterion is, in turn, meant to emerge from the empirically established common characteristics of the films. (Tudor 18)

This problem is due to the fact that genres are not just a formal phenomenon; they are not just films that share the same formal characteristics. They also are historically anchored representations, that is, spectators discovering a new film identify it as a road movie because they have already watched some road movies before. This implies that genres are not universal givens: each genre emerged at a given period of time and is constantly evolving. However, there is a third dimension of genres: viewers consider a film as a road movie because this film corresponds to their idea of what the road movie is. As Andrew Tudor stated, "the crucial factors which distinguish a genre are not only characteristics inherent to the films themselves; they also depend on the particular culture within which we are operating. [...] Genre is what we collectively believe it to be" (Tudor 19). Hence, film genres are produced by the discourses which describe them. Rick Altman (54-68) has shown that the promotional discourses produced by the film industry (in trailers, interviews, posters, and the like) tend to stress the polysemy of each film, in order to target as wide an audience as possible; hence, genres are only one aspect of these discourses. Critical discourses, on the other hand, tend to narrow down the expectations suggested by promotional discourses, as Janet Staiger pointed out: "film reviewers are functioning as surrogate consumers, following up on the promotion and publicity generated by the studios and affirming or denying the proposed reading strategies to counsel viewers about what they will see" (Staiger 12). Hence, critical discourses are an essential source of information on the generic framework which was associated with a specific film when it was originally released.

Starting with a list of films fitting the tautological definition highlighted above ("road movies are films in which traveling is a central element"), and studying their critical reception, it is possible to ascertain that the label "road film" (or "road movie," or "road picture") did not exist before the 1970s. Indeed, pre-1970s films about traveling on the road were linked to other generic frameworks and should be considered as the road movie's forerunners. For instance, Frank Capra's It Happened One Night (1934) was described by the Production Code Administration as a "transcontinental bus melodrama" (Wingate), while Variety called it "another long distance bus story" (Variety 26 February 1934) and the Motion Picture Herald, a "light, fast-moving comedy drama" (Aaronson). Similarly, John Ford's The Grapes of Wrath (1940) was regarded as a social problem film and a literary adaptation (Hollywood Reporter); Jerry Logan's Bus Stop (1956) was analyzed as "a booming comedy" with a "modern Western background and rodeo atmosphere" (Crowther); and Arthur Penn's Bonnie and Clyde (1967) was described as a "biopic" (Variety), a "picture of "mature violence"” (Alpert), a "thinking man's gangster film" (Lipton), an "action film" (Boxoffice), "a story of love on the run" (Kael), and "a watershed picture, the kind that signals a new style, a new trend" (McCarthy), but never a road movie. 
While reviews of Bonnie and Clyde had been focused on generic indeterminacy, critics began to consider the theme of the road in some films as characteristic of a new genre when Easy Rider (Dennis Hopper, 1969) was released. As shown elsewhere (HuraultPaupe 2003 and 2006), Easy Rider's reception evolved from comparisons that differentiated it from contemporary biker films, through descriptions as a modern western or an heir of The Grapes of Wrath, to one review which described it as a "song of the road" (Schickel) and another which called it a "film on the road" (Mahoney). However, the expression "road picture" proper emerged in September 1970, in critical discourses produced on Bob Rafelson's Five Easy Pieces. ${ }^{1}$

In brief, defining road movies as films that have historically been designated as such when they were first released - either by their producers, or by the American press makes it possible to circumscribe an international corpus from 1969 to the present day, including but not limited to such films as Two-Lane Blacktop (Monte Hellman, 1971), The Sugarland Express (Steven Spielberg, 1974), Kings of the Road (Im Lauf der Zeit, Wim Wenders, 1976), Paris, Texas (Wim Wenders, 1984), Leningrad Cowboys Go America (Aki Kaurismäki, 1989), Thelma and Louise (Ridley Scott, 1991), A Perfect World (Clint Eastwood, 1993), The Straight Story (David Lynch, 1999), Gerry (Gus Van Sant, 2002), The Motorcycle Diaries (Diarios de Motocicleta, Walter Salles, 2004), Little Miss Sunshine (Jonathan Dayton and Valerie Faris, 2006), and Into the Wild (Sean Penn, 2007).

\section{Defining filmic movement}

7 In order to study movement in the road movie, it is first necessary to differentiate the various sorts of filmic movements perceived by spectators. ${ }^{2}$ However, this typology is provisional, as its usefulness will then be tested by analyzing specific segments.

The first, and most pervading, type of filmic movement, which will be called durationinduced movement in the present article, is the sense of motion that spectators derive from the very duration of a film. This movement is always there, no matter how still the image is. Indeed, Gilles Deleuze has demonstrated that movement is an inherent quality of the filmic image: spectators in a movie theater are faced with motion pictures and cannot perceive the individual still frames which are projected on the screen: "Cinema does not give us an image to which movement is added, it immediately gives us a movement-image. It does give us a section, but a section which is mobile, not an immobile section + abstract movement" (Deleuze 1997, 2). Filmic movement cannot be separated from its temporal dimension and from the sense which spectators have, even if there is no visible movement, that what they see on screen is likely to change at any time:

The moving image is an image in perpetual transformation that permits us to see the represented object's passage from one stage to another. (This movement thereby requires a temporal dimension). The represented object in the cinema, therefore, is always in the process of becoming represented. By the simple fact of being filmed, every object and every landscape, no matter how static, is inscribed within a specific duration and is thus a subject of transformation. (Aumont et al. 69)

Hence, as Garrett Stewart has noted, even freeze frames - in which the same frame has been duplicated in the projected reel in order to give the impression that the image has stopped -are based on duration-induced movement: they are "the paradoxical case of 
real motion without real movements that merely takes the condition of cinema to its limit" (Stewart 19).

Secondly, filmic movement may be thematic, that is, it may play a central role in the characters' personality and existence. This thematic conception of filmic movement dominates in the research dominated by tautological definitions of the road movie (Cohan and Hark, Laderman, Mills, Sargeant and Watson, Orgeron, Thoret and Benoliel), as this research is based on the hypothesis that traveling organizes the protagonists' psychology and lives. However, as the third part of this essay will explore, thematic filmic movement is not always a relevant criteria when discussing movement in the road movie.

11 Thirdly, filmic movement may refer to the spatial translation, in front of the camera and within the frame, of characters and/or objects. Using an adjective coined by Etienne Souriau (Souriau 8) but redefined by Jean Bessalel and André Gardies (171-172), I will call it profilmic ${ }^{3}$ movement. However, in the case of talking films especially, profilmic movement may be purely audible: even when no visible profilmic movement (as defined above) is perceptible, movement may be suggested by the soundtrack, for instance when characters known by the viewers, but located off-camera, are moving towards the camera: an increase in the sound of footsteps when no character is shown, for instance, frequently means that someone is moving nearer. ${ }^{4}$ I suggest calling this audible off-camera movement.

12 The fourth type of filmic movement, camera movement, is caused by the camera itself, and may be totally independent of character movement. It is a movement of the frame itself. As Kenneth Johnson has shown (using a term coined by Seymour Chatman), when the camera detaches itself from a character's point of view and becomes a "wandering camera," it reveals the presence of an enunciatory activity and thus implies the presence of a filmic narrator distinct from any of the characters. In this case, the independent movement of the camera (independent of any character's point of view) generates the spectators' awareness of a "presence," that of an omniscient narrator. Therefore, it might be said that the "wandering camera" generates a cognitive movement. The present article will seek to identify traces of "wandering camera" by considering whether camera movements in the sequences studied are always attached to the characters' movement. If wandering camera is encountered, I will examine whether it implies an omniscient narrator and/or an authorial presence.

Fifth, spectators may derive a sense of movement from a film because its images are dominated by asymmetric or diagonal lines that focus attention on offscreen elements. In this case, it is the composition of each shot, that is, the overall effect produced by a specific combination of graphic elements, which produces a dynamic impression. Hence, this movement may be referred to as composition-induced movement.

It is also necessary to consider, as a sixth category, what may be called editing-induced movement. This category includes the sense of rhythm created by the succession of shots (for instance, if shot length steadily decreases in a sequence, this creates a feeling of acceleration, etc.) and those matches that are specifically linked with movement, either because they replace a physical movement (the eyeline match), because they give a feeling of moving closer (the American cut), or because they replace a continuous camera movement (the match on action). Differentiating compositioninduced movement from editing-induced movement makes it possible to envisage that film movement is not entirely grasped by the opposition between stasis and dynamism. 
Indeed, while comparing paintings and films, André Bazin (188-189) contrasted the use of a frame ("cadre") in paintings with the use of a mask ("cache") in the cinema, showing that the pictorial space in paintings is polarized towards the inside of the frame, whereas the filmic space is oriented towards the outside, because it implies an endless virtual universe that encompasses the filmic image. Bazin concluded that "paintings are centripetal; films are centrifugal." However, this theory has been contradicted in particular by Jacques Aumont (115), who suggested replacing Bazin's opposition by the notions of the frame as limit ("cadre-limite") and the frame as window ("cadre-fenettre"), and who underlined that the pictorial and filmic images partake in both types of framing, very often at the same time. Following Aumont's qualification of Bazin's terminology, in the present article, films segments (made of several shots) will be considered as centripetal if shot composition and editing construct a movement towards the center of the frame, and they will be called centrifugal if shot composition and editing generate a movement towards off-frame and/or off-screen space. My hypothesis will be that films with a centripetal esthetics generate less of an impression of movement than those with a centrifugal esthetics.

Seventh, spectators are also aware of the narrative flow of films, which may be defined as the succession of filmic segments which maintain focus on the unfolding of the story and on action. Narrative movement may be causality-driven, as was the case in most classical Hollywood films where the hero, who was the center of a continuous movement, was faced with a conflict and took action to change his or her environment (Elsaesser 289-290). Deleuze has called image-action the type of narrative movement that is typical of classical cinema (characterized, to him, by the dominance of the "movement-image"), where narratives are logical and causality-driven: characters are faced with problematic situations, which they solve, leading to new narrative situations. However, even in classical Hollywood films, not all sequences are narrative: as Laura Mulvey has stressed, there are often segments during which narrative action is replaced by the spectacle of the female body. Similarly, Mary-Ann Doane has pointed out that the close up may serve to interrupt narrative flow. Such interruptions are more frequent in modern cinema ${ }^{5}$, where narrative movement may be almost or totally non-existent. Deleuze, writing about Italian neo-realism and 1970s New Hollywood cinema, has showed that the logical narrative flow of the classical cinema was replaced by the "crisis of the action-image," which led to the appearance of some films which were organized by the "bal(l)ad form" (Deleuze 1997, 205-211). To him, these films were characterized by meaningless events and frequent apparently pointless stops in the narrative flow, as well as by the aimless, unpredictable movement of their protagonists, the subjection of the protagonists to events over which they have no control, and the use of anonymous spaces. Deleuze mentioned some road movies as typical of the bal(l)ad form: he saw Easy Rider as an early, partial, example, and also referred to Alice in the Cities (Alice in den Städten, 1974) and Kings of the Road (Im Lauf der Zeit, 1976). Consideration of narrative flow in the present article will therefore focus on whether or not the narratives under study are causality-driven, and focus especially on segments of narrative stasis or aimless movement.

This typology will now be used in order to assess what type of movement appears in road movies. More specifically, what are the type(s) of filmic movement which make such statements as "the road movie is a static genre" or "the road movie is a dynamic genre" valid? 


\section{Are the typical sequences of road movies static?}

The most emblematic type of sequence in the genre is the "road sequence," a fragmentary and elliptic editing sequence dealing with the movement of characters in road movies (Hurault-Paupe 2006, 399). Such segments usually occur several times in each road movie. A typical example can be found in Easy Rider (Dennis Hopper, 1969) where two bikers, Wyatt (Peter Fonda) and Billy (Dennis Hopper), are traveling from Los Angeles to New Orleans in order to participate in the Mardi Gras festivities, and have taken along with them George (Jack Nicholson), an ACLU lawyer. The sequence under analysis ${ }^{6}$ shows them cycling through Western landscapes (in a first, shorter segment), then, after crossing a bridge, driving through a Southern city. Each segment is edited to a different song. The soundtrack for the first segment is "Don't Bogart Me" by the Fraternity of Man, the lyrics of which describe the pleasures of marijuana. During the second and longer segment, Hopper uses Jimi Hendrix's song "If Six Was Nine", the lyrics of which express distrust towards both hippies and white-collar conservatives.

This sequence is linked to mobility by the theme of traveling through a city, as well as through the visible profilmic movement of the bikes. However, the first shot in the sequence is very static, as everything is in focus from the bikers in the foreground to the desert in the background. The extremely flat landscape enhances this impression of stasis. When the characters start driving, the camera mostly films in lateral tracking shots showing the sides of the road, with or without the bikes in the foreground, periodically combining this movement with jerky zoom-in movements on details (for instance, there are two such zooms on the American flag). The composition of each shot leads the spectators' gaze towards the edge of the frame and only reveals the roadside in fleeting views, which creates a dynamic effect.

Yet, the editing cuts these fleeting views of the roadside in a way which suggests that the camera has to keep up with the profilmic movement of the bikes. Therefore, space is vectorized along the linear trajectory of the road, hence, paradoxically, an overall impression of editing-induced centripetal movement.

Narratively speaking, this sequence combines the notion of abrupt changes with that of the roadside as a spectacle. On the one hand, there are two pivotal moments when the sequence introduces the idea of narrative change. First, when the second song begins on the soundtrack, a low-angle shot of a metallic bridge is shown, leading the viewer to expect the characters to enter a different type of space. This expectation is reinforced by the fact that one shot in the credits sequence showed the characters crossing the Colorado River as a symbol of their entering the West: the motif of the metallic bridge has already been associated with narrative change. The expectation is immediately confirmed by shots of the bikers driving through the Southern city. The second shift takes place when, after driving by a cemetery, the bikers slowly leave the shoulder of the road and drive onto a two-lane road, entering a more rural area. This transition leads them to the outlying African-American section of the city. Such discontinuity confers added dynamism on this sequence.

21 Although the viewer already knows that the bikers are driving through the Southwest towards New Orleans, this sequence introduces the idea of urban segregation, which is necessary to narrative flow, as it is linked to the xenophobia leading to the 
assassination of George by rednecks later on in the narrative. Similarly, there are two shots on cemeteries (one just before the characters enter downtown, and the other when they leave town), which act as prolepses to George's death. On the other hand, the succession of shots repeating the same actions (driving and watching) belongs to the realm of the spectacle, as does the long, static first shot. Overall, however, narrative flow dominates, as key information is conveyed by this sequence.

This sequence can be interpreted as evidence of the "aesthetics of curiosity" typical of the road movie, because it shows the roadside to the spectators (Hurault-Paupe 2006, 392-398). Using a movement-based approach makes it possible to qualify this statement: while the "aesthetics of curiosity" can be seen as a centrifugal attitude, this is contradicted by the editing-induced centripetal movement present throughout the sequence. All in all, the dynamism of the road sequence is tempered by the accumulation of centripetal elements.

The same conclusion may be drawn from the analysis of other road sequences in the genre: generally, the thematic and profilmic movement of the characters is contradicted or tempered by the editing and composition of shots. For instance, the first road sequence in David Lynch's A Straight Story shows the protagonist launching his trip through immense landscapes that dwarf him, thereby reducing his already slow advance to an almost insignificant movement. Similarly, in Richard Sarafian's Vanishing Point (1971), the hero's speeding car is often filmed in extreme long shots and with extremely slow pan shots which make its profilmic movement seem insignificant. All these elements account for the fact that road sequences are paradoxically, if not static, at least centripetal.

The second type of sequences typical of road movies is halt sequences, in which the protagonists stop somewhere. These sequences by definition alternate with road sequences. Such a sequence can be found near the beginning of Two-Lane Blacktop. In this film, the protagonists, called the Driver and the Mechanic, drive haphazardly from one illegal car race to another, after having left Los Angeles. A third character, the Girl, climbed on board their automobile one day when they had stopped for food. The segment under analysis takes place when they stop in Santa Fe. ${ }^{7}$ The Girl gets off the car at the city's Plaza to go and beg money from tourists, then runs off towards the background, crossing the Plaza.

This sequence is clearly not necessary in the narrative flow, except to confirm that the Girl is a beggar. Shot composition in this sequence is static, as there is an accumulation of static shots with frames within the frame (formed by the car's windshield, poles, the pillars of the square, the windows behind the Indians, the carpets on the ground, and the scenic disposition of the Plaza with a stage in the middle).

Interestingly, however, movement remains thematically present, for instance when the Girl begs for money (she claims she need money for the bus back to San Francisco). There are visible profilmic movements: the boys drive away; the Girl walks towards the Plaza; then, after begging, she runs away. These profilmic movements are followed by the camera, hence a relatively dynamic dimension. The editing reinforces this sense of dynamism, but in quite an unusual way: first, when the boys drive away, they go towards the left, but then they are shown driving to the right. This attracts viewers' attention to the right side of frame. After the high angle shot following the Girl, the editing cuts to a shot on some Indian sellers, sitting near the right edge of the frame. During this, the voice of the Girl can be heard off-camera to the left; then there is a cut 
back to a now static high angle shot of the Girl begging. After another cut, the camera follows the Girl as she runs away. In sum, the editing confuses the spectators' sense of the spatial organization of this sequence, while also attracting attention to the shot on the Indian sellers. This shot is a token of realism, reinforced by a Mexican music which is heard at the beginning and at the end of the sequence and by the improvised dialogue, as well as by the fact that the actress (Laurie Bird) was nonprofessional and was talking to actual tourists. The aesthetics of curiosity is thus communicated to the viewers, as the editing creates a metanarrative shift away from the Girl's point of view and implies an enunciative slant in favor of an almost-documentary esthetics.

Enunciative digressions which stop the narrative flow while reinforcing verisimilitude are a recurrent feature of road movies. Similarly, road sequences repeatedly include halt sequences that foreground interrupted movement. This explains the iconographic recurrence of scrapyards in the genre. For instance, in a sequence located not long after the beginning of Richard Sarafian's Vanishing Point ${ }^{8}$, the hero, Kowalski, is chased by the police and knows that there is a roadblock intended to stop him. He drives through a fence into the desert and arrives in a scrapyard. He climbs out of his car, lays his hand on an old jalopy and looks pensive, then starts again, coming upon a railroad track, driving over flares burning on the road and past a STOP sign, without ever stopping. Then, as his car passes another car going the other way, his car is erased from the image, and only the other one remains. This sequence is then followed by a series of flashbacks explaining what led Kowalski to being chased by the police.

Thematically speaking, this sequence highlights imprisonment: Kowalski "can't get away," as a highway patrolman says on the radio. The symbolically dead cars in the scrapyard suggest that Kowalski is contemplating suicide (which is confirmed later on in the film). The close up on the STOP sign reinforces this idea. The audible off-camera presence of the police helicopter in some shots highlights the absence of an escape route. Camera movements are scarce and discrete, mostly to follow the cars' trajectories. Throughout, this sequence is dominated by static shot composition: first, when Kowalski makes a U-turn, the contours of the road correspond to the vanishing points of the image, leading the viewers' gaze towards a vanishing point located near the center of the horizon, and the overall impression is therefore centripetal. Then, when Kowalski stops in the scrapyard, the rusty and damaged vehicles are arranged around him, in a very static composition. When he leaves again, the horizon is constantly blocked (by a train, by a STOP sign, then by the presence of the helicopter hovering in the sky). Finally, when Kowalski encounters another car and is erased from the image, the road is seen in profile and the image is symmetrical.

However, the editing may at first sight be interpreted as contradictory to this overall static and centripetal impression. Indeed, shots showing nearly imperceptible profilmic movement alternate with blurred shots emphasizing the cars' speed. Only in hindsight can the viewer understand that the alternation of fast and slow segments leads inexorably to Kowalski's symbolic disappearance, and to his probable death, which by definition means the absence of movement. From a narrative point of view, this sequence is causality-driven: Kowalski is chased, makes a decision, and vanishes. Even though the freeze frame stops the narrative flow, it creates narrative expectations, and the flashback in the next sequence is no surprise. The interruption of narrative flow, which is renewed in the flashbacks that follow, therefore points at the final stop due to Kowalski's suicide, hence a static overall impression. 

to be the hero's quest. This is visible in Paris, Texas. The protagonist, Travis, has amnesia. He has been found in the desert and nobody knows where he was in the previous four years. His brother Walt comes to take him back to Los Angeles, but Travis keeps escaping and walking stubbornly toward an unknown direction. He disappears during a halt in a motel. The sequence ${ }^{9}$ begins with a series of seven shots in which Walt leaves the motel, finds Travis walking on the railroad tracks, and manages to convince him to get into the car. Then, a slow and long tracking shot forward shows the car driving and stopping at a motel.

31 the motel, through Travis's mysterious progression on the tracks, to the car's driving towards the horizon. Thematically, Walt's pragmatic trajectory can be contrasted with Travis's wandering: the sequence opposes traveling back to civilization (represented by Los Angeles) to escaping towards the wilderness (epitomized by the Mohave Desert). It could therefore seem logical to consider this sequence as dynamic.

ambiguous. At first, four shots highlight off-screen elements by showing the characters walking towards the right and looking off-screen to the right. Then, the tracking shot forward is centripetal, as it is dominated by the contours of the road leading to a vanishing point at the center of the horizon, but the car leaves the road to the right when it stops in front of the motel. Finally, the next shot shows Travis sitting absolutely still on a bed covered with a checkered plaid, and wearing a checkered shirt. His back is to a white brick wall and the rectangular shapes of the bricks are visible, so that this shot contains an accumulation of squares and rectangles which conveys a static impression. The editing of these shots therefore constructs a general movement from left to right, better to trap Travis inside the movement back to civilization which is enforced on him. Travis's wandering impulse has been harnessed back into Walt's conventional trajectory.

sequence is dominated by still shots, and when the camera moves, it does so very slowly, either to discretely follow characters, or because it has been placed inside the car; hence a paradoxical feeling of stasis. Finally, this sequence serves no narrative purpose, as viewers already know that Travis keeps walking down imaginary or real lines through the landscape. The long tracking shot forward is accompanied by the plaintive bottleneck guitar tune which has been associated to Travis since the beginning of the film, and its color scheme is dominated by various shades of orange and purple, so that it has a hypnotic effect on most viewers, who are captivated by the sheer spectacle of movement.

Indeed, the narrative flow of road movies incorporates frequent sequences during which the action proper is stopped although the characters keep driving. This is the case for instance in Vanishing Point, when there are long segments showing Kowalski's driving through the desert. His car is filmed in aerial shots, in extreme long shots that make it appear as a dot progressing through the flat white surface of the desert, and the idea that his driving is aimless and pointless becomes obvious when he crosses his own track. The same idea of a slow endless movement forward into a desert has been used as the pretext for an entire film in Gerry: the two protagonists, both called Gerry, have lost their way while hiking haphazardly through the desert. When they try and walk through a salt lake in the hope of finding a road, they get even more lost. Finally, one of the Gerries, who had become too weak after days in the desert, is killed by the 
other, who does eventually find a road. Throughout the film, the camera records a mineral time in which man is insignificant; this is underlined by shots of the fast profilmic movement of the clouds, as opposed to the slow progression of the protagonists. In the last part of the film, shot duration is extremely long, so that our attention is drawn to the small variations of the light, the sky, the ground, and the mountains, which shows that human movement is nothing and that, through duration, natural movement annihilates $i^{10}{ }^{10}$. As in Paris, Texas, the frequently monochromatic image focuses our attention on their movement. However, in Gerry, this underlines the physical fragility of the characters.

Some road movies are dominated by wandering, so that plot events are by definition unpredictable in these films. Brutal accelerations and long pauses are both possible. The common point is a lack of causality and the succession of plot events as discrete episodes, not in a causality-driven flow. Five Easy Pieces is a case in point. The protagonist, Bobby (Jack Nicholson) is presented as an oil rig worker who is dissatisfied with his life and who cheats on his girlfriend. The sequence under analysis ${ }^{11}$ begins one morning when he is driving to work with his friend and colleague Elton. Bobby, who is driving, has to stop when they reach a traffic jam on the freeway. Angered, Bobby exits the car and yells at the honking drivers around him. When a dog starts barking at him from inside a passing car, Bobby snarls and barks at it as if he had become a dog himself. After climbing onto a truck to assert the size of the traffic jam, he discovers a piano which is being transported on the truck, and starts playing. When the truck exits the freeway, Bobby continues to play. The next sequence shows him climbing down from the truck in town in the evening.

One might think that Bobby's escape from routine generates a dynamic impression, but studying the treatment of movement in this sequence shows that such is not the case. The profilmic and thematic elements in this sequence are organized by the opposition between the routine trip (going to work) and the unplanned detour. The traffic jam symbolizes the boredom generated by daily repetition and is used as a scenic device for Bobby's temper tantrum, illustrating his restlessness while at the same time constraining it. The mostly static shots emphasize the actor's performance as he shifts from one role to the next (from a worker to a dog, then to a pianist). Camera movement is scarce and discreet, highlighting the fact that the cars are stalled. Shot composition emphasizes the character's entrapment by using the contours of windows, windshields, lanes, and vehicles as frames within the frame. The shots showing the endless lines of cars in the traffic jam are centripetal and static. The impression of being surrounded on all sides in enhanced by the omnipresent honking of cars. The editing of this sequence reinforces its static character, as a shot-countershot logic is followed, alternating between Bobby and Elton. Every action undertaken by Bobby is shown to have an effect on Elton, who laughs, applauds, and finally tries to warn Bobby that the truck is leaving the freeway, so that Bobby's centrifugal trajectory is compensated by Elton's centripetal point of view on it. Consideration of the trajectories in this sequence and the next confirms that this detour is dominated by stasis. Indeed, Bobby does leave the freeway at the end of the sequence, exiting the frame to the right. Yet, the next sequence begins with a dissolve in which the image of vehicles driving on the freeway towards the left of the horizon is slowly replaced by a shot of the truck driving into the frame from the right to the left, so that, thanks to this matching action, Bobby's detour into the unplanned ends with a return to routine. Similarly, while it is true that this 
sequence is part of a build-up leading to Bobby's departure from California, it stands outside a strictly causality-driven logic and corresponds to a lull in the narrative flow.

Even in road movies whose plot is dominated by a chase, movement can annihilate itself, as is the case in Thelma and Louise. In the last part of the film, the heroines, who have just learned that they are wanted for murder, have decided not to surrender. The sequence under analysis ${ }^{12}$ shows Thelma contemplating the mountainous landscape from her window and looking at the landscape behind them receding in the sideview mirror, and then stating that she has never felt this awake. Thematically, this sequence articulates the heroines' tragic enjoyment of freedom, knowing that they will probably be shot by the police or, at best, captured. It is fast cut and edited to quickly rhythmic extra-diegetic music. However, shot composition exploits the graphic rectangles which split the image into several zones, entrapping Thelma inside the car. The frequently blurred lateral tracking shots make the beauty of the landscape seem transient, while creating the impression that the landscape, not the car, is moving. Most interesting is the tracking shot forward that shows the image of the landscape reflected in Thelma's sideview mirror: in this frame within the frame, the landscape behind the car appears as blurred and mobile, in an artificial movement that is the reverse of the car's forward movement. Neither image is in focus, so that the overabundance of blurry movement paradoxically annihilates the viewer's perception of change. Therefore, movement in this sequence appears as perpetually "being done," and never leading anywhere. The editing is based on continuity and uses eyeline matches between Thelma and the landscape or mirror, which reinforces the sense that all the elements of the image are somehow equivalent, and that the contradictory movements we see cancel each other. Therefore, this is a road sequence which is about the annihilation of movement. This is confirmed by the fact that this sequence has no immediate narrative purpose, apart from acting as a prolepsis to the heroines' final annihilated movement, when they surge into Grand Canyon.

\section{Conclusion}

Through these examples, we have seen that the road movie is indeed thematically dominated by movement and that profilmic movement is frequent in its characteristic sequences. However, this dynamism is most frequently tempered by the accumulation of static and centripetal elements in shot composition, and by editing patterns which organize sequences along the linear trajectory of the road. Besides, the centrifugal aesthetics of curiosity remains a quantitatively secondary component of the road movie, as it is frequently compensated by segments in which the viewer is hypnotized by the sheer spectacle of driving.

These conclusions make it possible to understand the limits of the typology adopted above: first, duration-induced movement did not prove to be very useful to study these examples. Second, the existence of thematic and profilmic movement does not warrant that the film in question will be formally and structurally dominated by motion. Third, composition-induced stasis is easy to establish (by noting the accumulation of frames within the frame, for instance), whereas the existence of composition-induced movement is more difficult to show, because dynamic compositions leading off-camera in one direction in a shot or series of shots are frequently contradicted by the use of similarly dynamic compositions leading in exactly the opposite direction in the next 
shot or series of shots. This demonstrates that editing-induced movement is the most important criterion for deciding whether a film is static or dynamic, and whether it follows a centripetal or centrifugal logic. Any consideration of editing necessarily takes into account shot composition and camera moves. The notion of narrative flow would also have to be qualified: the example of Five Easy Pieces showed that unpredictable detours in road movies, while they have no immediate bearing on the cause-and-effect development of the narrative, play a significant role in narrative flow. Similarly, those road movie sequences which are dominated by an almost-documentary esthetics cannot be said to be devoid of narrative possibilities at the scale of the movies themselves. Finally, it would be worth pondering whether those road movie sequences which display driving for the sake of driving and lead to contemplation of the road as spectacle can be considered as examples of the Deleuzian bal(l)ad form, even though they alternate with other scenes which advance the action.

\section{BIBLIOGRAPHY}

Aaronson. Review of It Happened One Night. Motion Picture Herald. 3 March 1934.

Alpert, Hollis. “Crime Wave.” Saturday Review. 5 August 1967.

Altman, Rick. Film/Genre. London: British Film Institute, 1999.

Aumont, Jacques. L'oeil interminable: cinéma et peinture. Paris: Librairie Séguier, 1989.

Aumont, Jacques, Alain Bergala, Michel Marie, and Marc Vernet. Esthétique du film. 1983. Paris:

Nathan, 1994.

------. Esthetics of Film. Trans. Richard Neupert. Austin: University of Texas Press, 1992.

Bazin, André. Qu'est-ce que le Cinéma ? Paris: Editions du Cerf, 1997.

Bessalel, Jean and André Gardies. 200 mots-clés de la théorie du cinéma. Paris: Editions du Cerf, 1992.

Bezard, Nicolas. “À perte de vue. Gerry de Gus van Sant”. Les Cahiers du Musée national d'art

moderne 112/113 (Summer/Fall 2010): 136-46.

Boxoffice. Review of Bonnie and Clyde. 14 August 1967.

Boxoffice. Review of Midnight Cowboy. 26 May 1969.

Canby, Vincent. “Film: Midnight Cowboy.” New York Times, 26 May 1969.

Chik, Caroline. L'Image paradoxale. Fixité et mouvement. Villeneuve d'Ascq : Presses universitaires du Septentrion, 2011.

Chion, Michel. Audio-Vision. Trans. Claudia Gorbman. New York: Columbia University Press, 1994.

Cohan, Steven, and Ina Rae Hark, eds. The Road Movie Book. London: New York, Routledge, 1997.

Crist, Judith. Review of Midnight Cowboy. New York Magazine, May 1969.

Deleuze, Gilles. Cinéma 1. L'Image-mouvement. Paris: Editions de Minuit, 1983. 
-------. Cinema 1: The Movement-Image. Trans. Hugh Tomlinson and Barbara Habberjam. 1986. Minneapolis: University of Minnesota Press, 1997.

Doane, Mary-Ann. “The Close-Up: Scale and Detail in the Cinema." Differences: A Journal of Feminist Cultural Studies 14:3 (Fall 2003): 89-111.

Elsaesser, Thomas. "Tales of Sound and Fury : Observations on the Family Melodrama." In Film Genre Reader. Ed. Barry Keith Grant. Austin: University of Texas Press, 1995. 278-308.

Hollywood Reporter. Review of The Grapes of Wrath. 23 January 1940.

Hurault-Paupe, Anne. "L'émergence du "road movie" : métamorphoses d'un horizon d'attente. De Easy Rider à Cinq pièces faciles." Cahiers de l'Atelier de Recherche sur le Langage de l'Image (ARLI) 3 (October 2003): 5-24.

-------. “Le road movie : définitions, structures, antécédents et évolution." Diss. Université Paris 10-Nanterre, 2006.

Johnson, Kenneth. “The point of view of the wandering camera." Film Journal 32:2 (Winter 1993): 49-56.

Kael, Pauline. "Bonnie and Clyde." New Yorker. 21 October 1967.

Laderman, David. Driving Visions: Exploring the Road Movie. Austin: University of Texas Press, 2002. Lipton, Edward. Review of Bonnie and Clyde. Film Daily. 7 August 1967.

Mahoney, John. "Easy Rider facing high profits, critical honors.” Hollywood Reporter. 26 June 1969.

McCarthy, Floyd. “The Shock of Freedom in Films.” Time. 8 December 1967.

Mills, Katie. The Road Story and the Rebel. Moving Through Film, Fiction, and Television. Carbondale: Southern Illinois University Press, 2006.

Orgeron, Devin. Road Movies: From Muybridge and Méliès to Lynch and Kiarostami. New York:

Palgrave Macmillan, 2007.

Sargeant, Jack, and Stephanie Watson, eds. Lost Highways : An Illustrated History of Road Movies. London: Creation Books, 1999.

Rossaak, Eivind. Between Stillness and Motion: Film, Photography and Algorithms. Amsterdam: Amsterdam University Press, 2011.

Schickel, Richard. “A Lyric, Tragic Song of the Road.” Life. 11 July 1969.

Souriau, Etienne. L'Univers filmique. Paris: Flammarion, 1953.

Staiger, Janet. "Hybrid or inbred: The Purity Hypothesis and Hollywood Genre History." Film Criticism 22:1 (Fall 1997): 5-20.

Stewart, Garrett. “Photogravure: Death, Photography, and Film Narrative.” Wide Angle 9:6 (1987): 11-31.

Thoret, Jean-Baptiste, and Bernard Benoliel. Road Movie USA. Paris: Hoëbeke, 2011.

Tudor, Andrew. “Genre.” In Film Genre: Theory and Criticism. Ed. Barry Keith Grant. New York: Viking, 1973. 16-23.

Variety. “Review: It Happened One Night.” 26 February 1934.

Variety. “Review: Bonnie and Clyde." 9 May 1966.

Variety. "Review: Midnight Cowboy." 14 May 1969. 
Wingate, James. Letter to William H. Hays in the Production Code Administration file for It Happened One Night. 25 November 1933. MS. Production Code Administration Files. Margaret Herrick Library, Beverly Hills, CA.

A Perfect World (Clint Eastwood, 1993, with Kevin Costner and Clint Eastwood)

Alice in the Cities (Alice in den Städten, 1974, with Rüdiger Vogler and Yella Rottländer)

Easy Rider (Dennis Hopper, 1969, with Peter Fonda, Dennis Hopper, and Jack Nicholson)

Five Easy Pieces (Bob Rafelson, 1970, with Jack Nicholson and Karen Black)

Gerry (Gus Van Sant, 2002, with Casey Affleck and Matt Damon)

Into the Wild (Sean Penn, 2007, with Emile Hirsch, William Hurt, Kirsten Stewart, and Vince Vaughn)

Kings of the Road (Im Lauf der Zeit, Wim Wenders, 1976, with Rüdiger Vogler and Hanns Zischler) Leningrad Cowboys Go America (Aki Kaurismäki, 1989, with Matti Pellonpää and Kari Väänänen) Little Miss Sunshine (Jonathan Dayton and Valerie Faris, 2006, with Abigail Breslin, Toni Collette, Steve Carell, and Greg Kinear)

Paris, Texas (Wim Wenders, 1984, with Harry Dean Stanton, Nastassja Kinski, Hunter Carson, and Dean Stockwell)

The Motorcycle Diaries (Diarios de Motocicleta, Walter Salles, 2004, with Gael Garcia Bernal and Rodrigo De La Serna)

The Straight Story (David Lynch, 1999, with Richard Fransworth and Sissy Spaceck)

The Sugarland Express (Steven Spielberg, 1974, with Goldie Hawn, William Atherton, Ben Johnson, and Michael Sachs)

Thelma and Louise (Ridley Scott, 1991, with Susan Sarandon and Geena Davies)

Two-Lane Blacktop (Monte Hellman, 1971, with James Taylor, Dennis Wilson, Laurie Bird, and Warren Oates)

Vanishing Point (Richard Sarafian, 1971, with Barry Newman and Cleavon Little)

\section{NOTES}

1. Although it featured two bus trips, Midnight Cowboy (John Schlesinger, 1969), which was released in the United States just before Easy Rider, was not described as a road picture by critics, who considered it as a critique of underworld city life and a literary adaptation: it was called "the sometimes amusing but generally sordid saga of a male prostitute in Manhattan" (Variety, 14 May 1969), a "brilliant and faithful film version of James Leo Herlihy's compassionate and comic about the lonely ones who walk faceless in the crowd" (Judith Crist, New York Magazine, May 1969), “a slick, brutal (but not brutalizing) movie version of James Leo Herlihy's 1965 novel [... where] the focus is on this world of cafeterias and abandoned tenements, of desperate conjunctions in movie balconies and doorways, and catchup and beans and canned heat" (Vincent Canby, New York Times, 26 May 1969), and a film which "graphically depicts the sordid world of New York male prostitutes [... and is] also a compassionate, brutally touching love story about two men" (Boxoffice, 26 May 1969).

2. This typology does not include the technological movement of the projector, which takes place in the projection room, because this movement is invisible to the spectators. 
3. Souriau's definition of the profilmic is : "tout ce qui existe réellement dans le monde mais qui est spécialement destiné à l'usage filmique; notamment: tout ce qui s'est trouvé devant la caméra et a impressionné la pellicule." Bessalel and Gardies's definition is: "tout ce qui a été effectivement organisé, arrangé ou mis en scène pour être filmé."

4. In Dolby surround, the movement of sound from one loudspeaker to the next produces the same effect. Audible off-camera movement is based on the "spatial magnetization of sound by the image" described by Chion (69-70).

5. Which is not a historical period, as classical forms are still found in mainstream films after the 1950s.

6. Easy Rider: 59:30-61:47.

7. Two-Lane Blacktop: 13:02-14:31.

8. Vanishing Point: 6:51-9:32.

9. Paris, Texas: 18:42-20:57.

10. Cf. Gerry, 85:25.

11. Five Easy Pieces: $16: 13-19: 58$.

12. Thelma and Louise: 102:06-103:25.

\section{ABSTRACTS}

This article suggests a typology of the movements perceived by spectators in films. Filmic movement may be: duration-induced, profilmic, audible off-camera, composition-induced, editing-induced, narrative, or thematic. This typology is applied to the road movie, that is, a film genre defined as comprising those films which were considered as road movies by American critics or by their producers when they were first released. This makes it possible to show that the thematic and profilmic movement in road movies is frequently contradicted by an accumulation of formal elements which make the genre esthetically static and centripetal. Finally, editing-induced movement proves to be the key criterion in deciding whether a film is static or dynamic.

Cet article propose une typologie des mouvements filmiques perçus par les spectateurs. Le mouvement peut être : induit par la durée, profilmique, audible mais hors-cadre, induit par la composition de l'image, induit par le montage, narratif ou thématique. Cette typologie est appliquée au road movie, genre qui est défini comme l'ensemble des films perçus en tant que road movies par les critiques américains ou par leurs producteurs au moment de leur sortie. Cela permet de montrer que le mouvement thématique et profilmique dans le road movie est fréquemment contredit par une accumulation d'éléments formels qui confèrent au genre une esthétique statique et centripète. Enfin, le mouvement induit par le montage s'avère être le critère déterminant pour décider si un film peut être considéré comme statique ou dynamique.

\section{INDEX}

Mots-clés: mouvement au cinéma, stase, dynamisme, genres cinématographiques

Keywords: filmic movement, stasis, dynamism, film genres, road movie 


\section{AUTHORS}

\section{ANNE HURAULT-PAUPE}

Université Paris 13, Sorbonne Paris Cité

Maitre de conférences

anne_paupe@yahoo.fr 